\title{
LIÇÕES DE DOIS PROCESSOS DE INTEGRAÇÃO: UNIÃO EUROPEIA E MERCOSUL
}

Luiz Strella Faria ${ }^{1}$

\section{Resumo}

$\mathrm{O}$ artigo analisa os dois processos de integração, o da União Europeia e do Mercosul, através de quatro aspectos: a) possíveis comparações e convergências; b) a participação das forças sociais nos blocos; c) a relação entre o processo de integração e o regime de acumulação de capital e d) os modelos institucionais distintos. $\mathrm{O}$ artigo, ao chamar a atenção para o fato que a literatura traz o processo de formação do bloco europeu como paradigma para outras experiências de integração no restante do mundo, destaca entre elas as possíveis comparações e convergências.

Palavras-chave: União Europeia. Mercosul. Modelo Institucional.

\section{Abstract}

The article analyses two processes of integrations, the European Union and Mercosur, in four aspects: a) possible comparasions and convergences; b) social forces participation of in the blocs; c) relations among the integration process and the capital's regime of accumulation and d) the different institutional models. The article, calling attention to the fact that literature focuses the process of construction of the European bloc as a paradigm for other experiences of integrations, emphasizes among them possible comparations and convergences.

Keywords: European Union. Mercosur. Institutional Model.

\footnotetext{
${ }^{1}$ Economista. Mestre em Economia pela Universidade Federal do Rio Grande do Sul. Doutor em Economia pela UFRJ. Técnico da Fundação de Economia e Estatística e professor associado da UFRGS nos cursos de pós-graduação em Economia e em Estudos Estratégicos Internacionais. É autor do livro "A chave do tamanho". Desenvolvimento econômico e perspectivas do Mercosul. http://www.ufrgs.br/ppge/ Email: lufaria@ufrgs.br
} 
A presente exposição é uma tentativa de fazer uma comparação entre os processos de integração da União Europeia e do Mercosul, tendo como objetivo identificar semelhanças e recolher algumas lições desses dois modelos ao mesmo tempo assemelhados e diversos. Para uma abordagem completa do processo, optamos por dividir a análise em quatro tópicos relevantes para estabelecer uma confrontação entre a União Europeia e o Mercosul.

Em primeiro lugar, quando observamos a literatura sobre os processos de integração, ela é majoritariamente produzida pela própria Europa, em função do peso que o processo de integração europeu tem na vida das pessoas. Não se trata somente de tradição acadêmica e de pesquisa dos grandes centros universitários europeus, mas, sim, porque este é um tema que diz respeito à vida de todas as pessoas no continente europeu. Embora também outro grande polo intelectual do mundo, os EUA vivam o seu processo de integração, o Nafta (Tratado de Livre Comércio da América do Norte), a natureza dos dois processos é bem diferente. Nos EUA, por exemplo, um cidadão estadunidense praticamente desconhece a existência do Nafta, porque esse acordo afeta minimamente a vida dos cidadãos dos Estados Unidos. Já para os mexicanos, o Nafta possui maior relevância, porque afeta muito mais suas vidas. Assim, como para os norte-americanos quase não tem relevância, é natural que o tema seja secundarizado pela academia daquele país.

Algo importante a chamar a atenção é que essa pesquisa europeia sobre o tema da integração traz na literatura o processo europeu como um paradigma que serve de comparação a qualquer outra experiência de integração no resto do mundo. Inclusive a forma como se construiu o processo europeu passa a ser um modelo a ser seguido por qualquer outro processo de integração que queira ser tão bem ou melhor sucedido que o caso da Europa; essa perspectiva traz um ponto importante para reflexão.

O primeiro aspecto a ser colocado para meditação e que serve de comparação e até mesmo de convergência nos processos de integração da Europa e América do Sul é que eles, por um lado, possuem uma forte motivação política em suas origens, mas também possuem uma predominância da economia na sua realização. Qual é o tema político na origem dos dois processos? No caso europeu, é encontrar uma forma de solução dos conflitos, das diferenças e da própria natureza competitiva do sistema interestatal europeu, encontrar uma forma de tratar esse problema que não fosse através da solução armada, opção histórica da geopolítica europeia até a $2^{\text {a }}$ Guerra Mundial. A guerra foi a forma predominante de disputa entre os principais Estados europeus. Então, o tema da paz aparece como causa fundadora do processo 
de integração europeu, boa parte da literatura faz referência a esse tema como a causa central da formação da União Europeia.

No caso do Mercosul, não se trata da questão da paz, porque não existiram grandes conflitos no continente durante o século 20, não entre Estados, fora o caso da Guerra do Chaco envolvendo Bolívia e Paraguai ou o conflito Equador-Peru mais recentemente. Os demais conflitos existentes estão mais categorizados como guerra civil ou insurreições, mas não guerras entre Estados nacionais diferentes. Portanto, o tema político da formação do Mercosul não é a paz, o tema principal da sua formação é a democracia. Porque quando surge a proposta do Mercosul, na segunda metade dos anos 1980, é exatamente o período em que estão se extinguindo as ditaduras do Brasil e da Argentina. Dessa forma, na aproximação entre Brasil e Argentina - que foi o primeiro passo para o Mercosul, assim como na Europa a Ceca formada por Alemanha, França, e o Benelux -, os seus protagonistas, os ex-presidentes Sarney e Alfonsín, tinham como objetivo criar uma salvaguarda para a continuidade do processo de transição para a democracia nos dois países.

Isso foi particularmente importante no caso da Argentina, porque nesse país a transição foi mais difícil em razão de o governo Alfonsín ter enfrentado diversas sublevações de militares tentando restaurar o regime ditatorial, coisa que no Brasil não aconteceu. Inclusive porque os militares brasileiros conseguiram, de certa maneira, manter um controle do processo de transição para a democracia para que não invadisse certas áreas que eles consideravam intocáveis, questões que prevalecem até hoje na política nacional; os temas dos direitos humanos, da memória histórica da nação, temas ainda interditos pelo peso dessa forma como se deu a transição do processo democrático no Brasil. Esse é um tema, portanto, estritamente político e temos então motivações políticas nos dois processos, o europeu e o latino-americano.

Uma segunda característica importante também é que a construção do processo de integração se dá pela forte hegemonia das relações econômicas entre os países, isso é mais explícito no caso europeu, mas os dois blocos são uma obra do capital, principalmente do grande capital. Existe em ambas as sociedades um fator predominante no processo de integração, é a ampliação das perspectivas e a aceleração no processo de acumulação e concentração de capital, principalmente para as grandes empresas dos dois blocos. Mesmo no caso do Mercosul, onde há um forte discurso anti-integração, e alguns desavisados atribuem tal posição às lideranças empresariais. Ora, tanto no Brasil quanto na Argentina, assim como também no Uruguai e Paraguai, na verdade, o setor empresarial é até hoje o grande ganhador 
nesse processo, ainda que os ganhos sejam mais concentrados para alguns países, o que é muito natural numa economia capitalista. E esse processo de concentração e aumento dos ganhos, na medida em que há um aprofundamento da natureza competitiva do processo, esse tende a se intensificar cada vez mais e em poucas mãos.

Uma terceira semelhança que podemos trazer para a reflexão e que aproxima esses dois processos de integração é que, nos dois casos, temos a liderança de dois grandes países. No caso europeu, os dois grandes condutores foram Alemanha e França. Um terceiro candidato, porém tardio seria a Inglaterra, contudo esta entrou muito depois e até hoje mantém uma série de diferenças em relação à visão da integração dos sócios continentais. A Inglaterra não faz parte da Zona do Euro, existe uma série de resultados e ganhos coletivos em que a Inglaterra está fora. Prevalece, assim, no caso europeu, muito o peso da liderança alemã e francesa, com um certo desequilíbrio aparentemente cada vez maior em favor da Alemanha, cada vez mais poderosa, principalmente depois de sua reunificação, possuindo um setor financeiro-produtivo bastante avantajado, que desequilibra a seu favor em relação à França.

Por outro lado, a França permanece tendo um peso político na cena internacional, e que, na maioria das vezes, é muito maior que o seu peso econômico, isto é, uma construção histórica da sociedade francesa e das suas lideranças.

No caso do Mercosul, temos na origem do processo os dois maiores países se unindo na criação do Programa de Cooperação e Integração entre Brasil e Argentina, que começa em 1986 e, posteriormente, se transforma no Mercosul, com a adesão de Uruguai e Paraguai na assinatura do Tratado de Assunção, na virada da década de 1990 e que entra em vigor em 1991. Diferentemente, a assimetria entre os dois líderes é muito maior: Brasil com 190 milhões de habitantes e Argentina com 37 milhões, com PIBs de diferença proporcional também semelhante, ressalvando-se que, do ponto de vista per capita, há uma vantagem para a Argentina, que tem um PIB per capita um tanto maior que o do Brasil. Apesar de todos os problemas e crises, levando à estagnação econômica nos anos 1980 e 1990 principalmente na Argentina, esta então seria uma terceira característica de comparação entre os dois blocos econômicos.

O segundo tópico a ser tratado é a participação das forças sociais dos blocos dentro do processo de integração. Claramente na origem tanto na União Europeia quanto no Mercosul, temos o predomínio do capital industrial. A grande indústria foi, sem dúvida, o seguimento social impulsionador e o primeiro grande ganhador desse processo; no caso europeu, a indústria alemã principalmente, seguida da francesa, dentre outras. Com o passar do tempo, o 
capital industrial irá gradativamente ceder espaço para o capital financeiro já em meados dos anos 1980, e esse processo passa a ocorrer também no Mercosul nos anos 1990. No caso europeu, o ingresso da Inglaterra, país largamente desindustrializado, irá reforçar o processo de hegemonia do capital financeiro.

Com relação ao Mercosul, desde as origens da integração o grande ganhador desse processo foi, sem dúvida, a indústria brasileira, até porque a longa estagnação quase destruiu o setor industrial da economia argentina, principalmente a indústria de bens de consumo duráveis, como equipamentos domésticos e automobilística, mas também a indústria de bens de capital e a de infraestrutura, essas hoje quase exclusivamente brasileiras. Se formos olhar os acordos sobre comércio e os protocolos específicos setoriais, estes favoreceram exatamente uma maior integração da estrutura industrial. Por exemplo, um setor central da nossa dinâmica industrial, o automotivo, está estruturado desde a aproximação do Brasil com a Argentina, com um protocolo específico que permitiu um salto de modernização e de ganhos de produtividade deste segmento industrial muito grande, a ponto de ter se tornado exportador, o que nunca havia ocorrido. Tínhamos uma indústria automobilística no continente capaz somente de abastecer o mercado interno, que era muito protegido, e, hoje em dia, esse setor consegue exportar, o que é um indicador de que ele, do ponto de vista de produtividade, de custos, de qualidade de seu produto, evoluiu realizando um processo de reciclagem bastante importante. Já bens de capital e infraestrutura, que são outros ganhadores do Mercosul, são absolutamente brasileiros. Não existe quase nenhuma indústria de bens de capital nos outros países do bloco, assim como nos ramos de infraestrutura, engenharia pesada, telecomunicações, onde a hegemonia brasileira é somente um pouco menor.

Restaria a pergunta: Essa é uma diferença grande entre Mercosul e Europa? Qual é o papel das forças sociais vinculadas ao mundo do trabalho dentro do processo de integração? Isso é claramente diferente nos dois casos: eles são, sem sombra de dúvidas, em larga medida diversos, porque no processo europeu, que começou num momento em que o pacto social europeu tinha permitido a consolidação de um conjunto de conquistas, de bem-estar social, do nível de renda, acesso a serviços públicos, dentre outros avanços sociais. Isso pouco evoluiu num primeiro momento no processo de integração, mas se formos olhar para quando Portugal, Espanha e Grécia aderiram ao bloco europeu, o que se propiciou foi uma elevação do nível de renda da classe trabalhadora desses países, para que eles pudessem criar condições de se integrar também socialmente ao resto da União Europeia. Certamente, a atual ampliação não está dando conta desse tipo de preocupação, até porque os tempos políticos são outros e o 
mundo do trabalho sofreu a enorme contraofensiva neoliberal, com vistas a reduzir os direitos dos trabalhadores. Então, as condições políticas de repetir aquele processo de inclusão social para integração ao bloco europeu em relação ao ingresso das sociedades do Leste que estão entrando na União Europeia, agora, já não existem mais.

No caso do Mercosul, houve historicamente um pacto social em dois países com ganhos mais evidentes do ponto de vista das condições sociais de vida dos trabalhadores para a Argentina e o Uruguai. Na Argentina, esse pacto foi quase destruído pela ditadura, enquanto no Uruguai a ditadura foi mais curta e não conseguiu desmontar o pacto de bem-estar. Esse pacto social ainda em larga medida continua existindo no Uruguai, ao passo que na Argentina a ditadura deixou uma trágica herança social. No caso brasileiro, o processo de integração social dos trabalhadores foi muito mais lento, porém o processo de integração não deixou de abrir espaço para o debate deste tema, criou-se, inclusive, uma Carta Laboral do Mercosul, para tratar também da inclusão do mundo do trabalho no processo de integração. Concretamente, o que conhecemos de avanço ainda é muito pouco e, nesse aspecto, temos uma diferença muito grande.

O terceiro ponto trata da relação entre o processo de integração e o regime de acumulação de capital vigente nas economias que estão se integrando. Dependendo da modalidade de acumulação hegemônica dentro das economias e das sociedades que o estão formando, o novo bloco integrado perseguirá caminhos bastante distintos. A natureza do processo vai ser diferente se tivermos um processo de acumulação extensivo, ou seja, em que o processo de acumulação se retroalimenta com pouco peso do mercado interno ou se tivermos um processo de acumulação intensivo em que o desenvolvimento do mercado interno é fundamental para o processo de acumulação do capital. Ou, então, se tivermos vocações e perspectivas econômicas diferentes para o desenvolvimento, da mesma maneira se a hegemonia do processo de acumulação for baseada no setor produtivo ou no setor financeiro, portanto, se tivermos um processo de acumulação produtivo ou financeirizado. Também o grau de extroversão do processo de acumulação, se ele for mais internacionalizado ou se mais introvertido, terá influência.

Isso irá gerar respostas então, respostas do ponto de vista da natureza do processo de integração completamente diferentes. Uma acumulação extensiva poderia se combinar bem com o regime extrovertido na medida em que seus excedentes de produção vão ser colocados em outro lugar, porque o mercado interno é menos significativo. Essa perspectiva é a que foi colocada como predominantemente no Mercosul em seus primeiros anos. Na verdade, a 
integração pode ser entendida como uma tentativa de realizar uma transformação do nosso processo introvertido, levado adiante ao longo do século $20 \mathrm{com}$ a industrialização por substituição de importações, para um modelo extrovertido, tentativa esta que, com a contínua estagnação econômica dos anos 1980 e 1990, fracassou. O crescimento mais recente que podemos observar hoje é um retorno ao processo mais introvertido, é um crescimento baseado na ocupação do mercado interno.

No caso europeu, nitidamente a história da integração foi uma história da pavimentação, da estruturação de um crescimento relativamente introvertido, mais voltado para o mercado interno. Podemos observar claramente, a partir dos anos 1980, uma mudança significativa: o grau de extroversão das economias europeias é cada vez maior, e a importância das relações exteriores é cada vez mais relevante para o processo de acumulação de capital e crescimento econômico.

Por fim, onde somos mais diferentes do modelo de integração europeu é no modelo institucional. A União Europeia estabeleceu desde o início um modelo institucional com características de supranacionalidade. O processo de integração foi sendo estimulado e construído por instituições que se constituíram acima das organizações estatais nacionais, e que receberam por delegação dos Estados uma série de atribuições e funções reguladoras e de direção política e econômica das atividades socioeconômicas dentro do continente europeu, que antes eram atribuições próprias dos Estados nacionais.

A política comercial foi unificada desde a instituição da união aduaneira, pois, com uma tarifa externa comum, se tem só uma política comercial, mas também uma série de outros campos da vida social, inclusive do ponto de vista de temas sociais, políticas públicas, dentre outras. Temos, por exemplo, uma Corte de Justiça Europeia que funciona também como uma $4^{\mathrm{a}}$ instância da resolução de conflitos que são levados à apreciação do Poder Judiciário. Embora não seja esse o propósito do tribunal europeu, uma vez que ele deveria tratar apenas de questões europeias e não servir como corte de apelação. Porém, até isso ele pode ser, dada a sua natureza de recurso jurídico de última instância no ordenamento jurídico europeu. As decisões desta corte são de cumprimento obrigatório e se sobrepõem à justiça e à autonomia dos Estados nacionais. A União Europeia possui também um parlamento, mas é a Comissão Europeia que decide os rumos e que é produtora de boa parte das normas do bloco e que se sobrepõe também aos Estados-membros, na medida em que as decisões ou normas emanadas das instâncias supranacionais da integração vão gradativamente se sobrepondo às normas dos Estados nacionais. 
O caso do Mercosul é diferente. O nosso processo foi estruturado em um modelo interestatal, embora existam organismos supraestatais operando no Mercosul: existem o Tribunal que funciona em Assunção, o Parlamento que funciona em Montevidéu e a Secretaria Executiva que é um órgão que tem seu quadro funcional próprio. No entanto, as normas são geralmente decididas por consenso entre os quatro Estados, por isso a dificuldade de elaborá-las, pois todos os Estados devem estar de acordo. Ainda mais, sua vigência depende também da internalização dessas normas nos direitos de cada Estado para que elas tenham aplicabilidade: o Mercosul não possui normas de aplicação imediata e automática em suas instâncias. Pode ser que isso mude em algum momento do futuro, porém o quadro atual é este. Nessa perspectiva da literatura de tornar a Europa um paradigma a ser seguido, o Mercosul, portanto, sofreria de uma doença congênita que o impediria de construir as necessárias entidades supranacionais para levar a cabo seu processo de integração.

A própria natureza do que é objeto da integração é menos perceptível no caso sulamericano, pois carecemos de uma identidade comum compartilhada por nossas sociedades. Embora existam somente duas línguas no Mercosul (ou três, se considerarmos o guarani falado pelos paraguaios), talvez a identidade sul-americana seja muito mais frágil do que a europeia, apesar de na Europa existirem diversas línguas, tradições, culturas e religiões. Um cidadão norueguês da Lapônia tanto quanto um italiano da Calábria têm uma noção bastante clara e arraigada de pertencer a uma entidade chamada Europa e de compartilhar uma mesma herança social e cultural, uma tradição e uma história comuns. É difícil dizer o mesmo de um argentino de Buenos Aires e de um brasileiro de Juazeiro do Norte.

A própria pregação ideológica do latino-americanismo tem pouco eco social. Os latino-americanos não se consideram como tal, suas identidades são muito mais ligadas às nacionalidades, brasileira, argentina, dentre outras, do que ao conjunto maior que é a América Latina. Portanto, do ponto de vista da identidade, essa construção é muito difícil para nós. Talvez por isso alguns cuidados foram tomados na condução do processo aqui, cuidados estabelecidos como princípios que norteiam nossa integração, que são flexibilidade e gradualismo. Pode-se admitir a hipótese de que esses princípios tenham a ver com isso, com a necessidade de um tempo de maturação mais dilatado do processo de identificação entre as sociedades, que dê um respaldo maior ao processo de integração.

Por outro lado, não deixou de ser surpreendente a velocidade com que o processo de integração foi se consolidando aqui, uma velocidade muito maior do que a da União Europeia. A União Europeia se consolidou em décadas e o Mercosul, em alguns anos. O Tratado de 
Assunção foi assinado em 1990 e, em 1995, entrou em vigor a tarifa externa comum, o Mercosul passou de uma região de preferências comerciais para uma união aduaneira em muito pouco tempo.

Portanto, temos claramente dois modelos institucionais muito diferentes, que talvez tenham a ver com a hipótese de termos uma identidade muito mais débil do que no caso da Europa, o que obriga os Estados nacionais do Mercosul a terem um papel central no processo de integração.

Quanto às perspectivas dos blocos, claramente parece haver uma hegemonia neoliberal na condução do processo europeu, em função das dificuldades relacionadas às divergências entre as forças políticas europeias. Um exemplo elucidativo é o caso recente da Grécia, para a qual foi posto em marcha um plano de recuperação econômica baseado em um modelo de austeridade fiscal, ao contrário do que reza a boa doutrina macroeconômica sobre o que deve ser feito em momentos de crise, justamente o momento em que o Estado deve gastar mais para manter os empregos e a atividade econômica. No caso grego, ocorreu exatamente o contrário.

Para o Mercosul, é diferente. Toda a América Latina atravessou uma longa crise entre os anos 1980 e os anos 1990 e que teve seu capítulo final na crise argentina em 2001 e na crise brasileira em 2002, essa controlada rapidamente. A resposta a isso foi uma mudança política em todos os países do bloco, assim como nos membros associados e na maior parte dos vizinhos sul-americanos.

A hegemonia das políticas neoliberais terminou em função da crise internacional deste modelo, que as forças políticas vinculadas ao grande capital e às finanças tentaram implantar nos países do Mercosul e que não funcionou. Esse modelo trouxe somente estagnação, desemprego e aumento da miséria. O desenvolvimento das novas forças políticas que ascenderam ao poder no novo século consolidou um caminho alternativo de superação, de colocar termo à hegemonia da acumulação financeirizada que se constituiu a partir de um processo em que as finanças alcançaram estar fortemente incrustadas no poder. O Brasil talvez seja o único país do bloco onde isso ainda ocorre, pois, na Argentina e no Uruguai, esse modelo perdeu força e, no Paraguai, nunca chegou a existir. Isso é o que marca hoje o Mercosul, há uma diferença política muito grande, as escolhas políticas majoritárias na Europa e no Mercosul são hoje muito distintas.

Talvez no futuro as sociedades europeias rearticulem-se no campo político e consigam reverter a grave crise social por que passam atualmente. 